\title{
Applications of microwave dielectric heating in environment-related heterogeneous gas-phase catalytic systems
}

\author{
Xunli Zhang ${ }^{a, b, *}$, David O. Hayward ${ }^{\text {a,1 }}$ \\ ${ }^{a}$ Department of Chemistry, Imperial College of Science, Technology and Medicine, South Kensington, London SW7 $2 A Y, U K$ \\ bepartment of Chemistry, The University of Hull, Hull HU6 7RX, UK
}

Received 30 January 2006; accepted 31 January 2006

Available online 15 March 2006

This paper is dedicated to Professor D. Michael P. Mingos (FRS).

\begin{abstract}
The application of microwave dielectric heating in a range of environment-related heterogeneous catalytic reaction systems has been reviewed. The reactions investigated include the decomposition of hydrogen sulfide, the reduction of sulfur dioxide with methane, the reformation of methane by carbon dioxide, the hydrodesulfurization of thiophene, and the oxidative coupling of methane. The interaction of microwave irradiation with heterogeneous catalytic systems and its consequence for the microwave heating behaviour of catalysts have been examined. The effect/mechanism of microwave dielectric heating on heterogeneous catalytic reaction systems has also been discussed.
\end{abstract}

(C) 2006 Elsevier B.V. All rights reserved.

Keywords: Microwave dielectric heating; Heterogeneous catalysis; Thermal effects; Hot spots

\section{Contents}

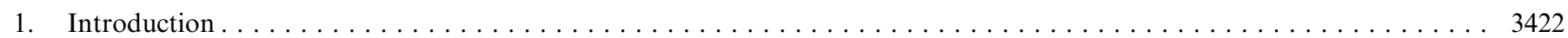

2. The interaction of microwave irradiation with heterogeneous catalytic systems $\ldots \ldots \ldots \ldots$

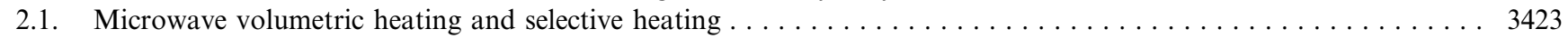

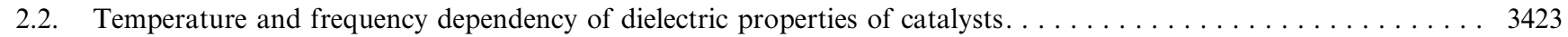

2.3. Characterization of microwave dielectric heating for heterogeneous catalytic systems. . . . . . . . . . . . . 3424

3. Applications of microwave dielectric heating in environment-related heterogeneous catalytic reactions. . . . . . . . 3425

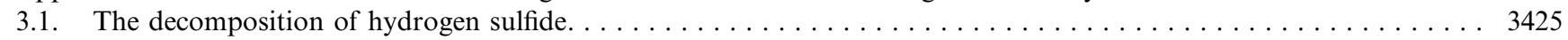

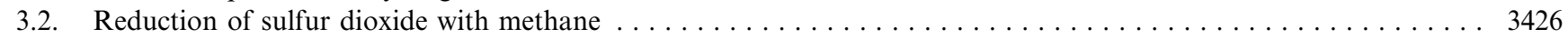

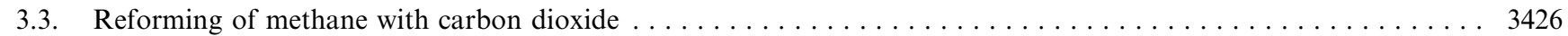

3.4. Hydrodesulfurization (HDS) of thiophene - an exothermic reaction $\ldots \ldots \ldots \ldots 27$

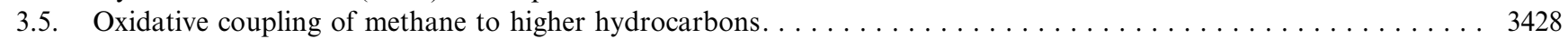

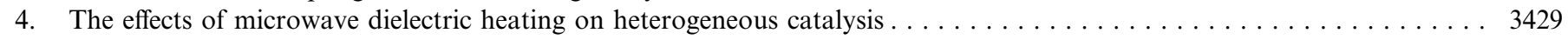

4.1. Temperature difference between catalyst and reactant . . . . . . . . . . . . . . . . . . . . . . 3429

4.2. Temperature difference between catalyst particles and catalyst support $\ldots \ldots \ldots \ldots \ldots$

\footnotetext{
* Corresponding author. Tel.: +44 01482 466409; fax: +44 01482466410.

E-mail address: X.Zhang@Hull.ac.uk (X. Zhang).

${ }^{1}$ Now retired.
} 


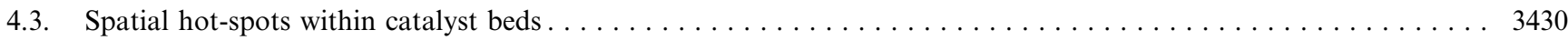

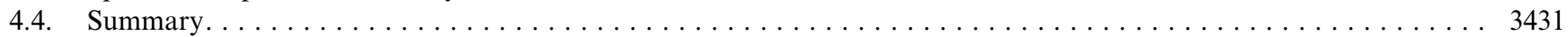

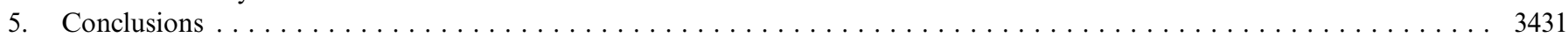

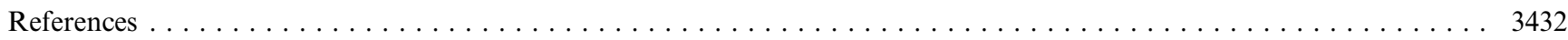

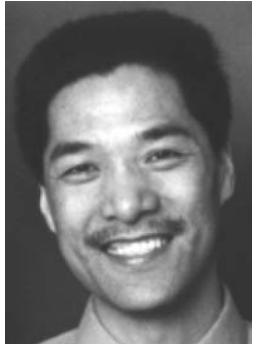

Xunli Zhang graduated from Northwest University, China, where he received his B.Sc. and M.Sc. in Chemical Engineering in 1987 and 1990, respectively. Upon receiving an ORS award in 1996, he started his Ph.D. studies at Imperial College of Science, Technology and Medicine, under the supervision of Prof. Mike Mingos (FRS). His Ph.D. research has focused on studies of heterogeneous catalysis using microwave and conventional heating, and has resulted in 14 papers published in peer-reviewed international journals. He was awarded a Ph.D. degree by the University of London in 2000. Dr. Zhang is currently working as a research fellow in the University of Hull with research interest in microfluidic and Lab-on-a-Chip technology. He has published more than 20 papers and patents in the related area since 2001.

\section{Introduction}

Microwave radiation lies in the range of the electromagnetic spectrum between infra-red and radio frequencies and corresponds to wavelengths of $1 \mathrm{~cm}$ to $1 \mathrm{~m}$ (frequencies of $30 \mathrm{GHz}$ to $300 \mathrm{MHz}$ ). Most of the industrial and domestic appliances are authorized to operate only at either $915 \mathrm{MHz}$ or $2.45 \mathrm{GHz}$ (wavelength 32.8 or $12.2 \mathrm{~cm}$, respectively) to avoid interfering with radar and telecommunication frequencies [1]. Domestic microwave ovens generally operate at a frequency of $2.45 \mathrm{GHz}$.

Microwaves were used initially for radar detection during the Second World War [1]. Microwave radiation as a remote heating source was developed subsequently and is well established in society in domestic microwave ovens and industrial systems. The application of microwave dielectric heating to chemical systems attracted great interest following the publication of two important papers in 1986 [2,3], although initial reports indicating the potential of the technique had been published in 1981 for chemical synthesis [4] and in 1967 for polymer applications [5]. Over the last decade, in particular, the development of microwave-assisted chemistry has witnessed an explosive growth, as detailed below.

(a) There has been a dramatic increase in the number of related research publications and the number of researchers involved. For example, there were about 50 papers published in this area in 1993, but this figure increased more than 5-fold in 2004, and to date, the total number of related papers is around 2000 [6]. It is estimated that, at present, about 2500030000 chemists use microwave technology to conduct chemical reactions worldwide [7]. (b) The research area has been extended to almost all areas of chemistry across synthesis, catalysis, analytical chemistry, materials, polymers, drug discovery, biochemistry, etc., and this is reflected in the number of reviews published [8-29], although more than half of the work has been focused on synthesis chemistry.

(c) There has been a notable increase in the use of more sophisticated equipment in microwave chemistry, for which there is a growing market. The increasing use of microwaves in chemistry has also aroused commercial interest in the development of specialized equipment for specific tasks. As a result, more and more microwave chemistry equipment is commercially available and is used in academic laboratories and laboratories in the chemical, pharmaceutical and biochemical industries. The market for microwave chemistry equipment was estimated to be $\$ 89 \mathrm{~m}$ in 2003 , and is expected to reach $\$ 145.8 \mathrm{~m}$ by 2008 with advancement in equipment technology and a growing awareness of technology, its success, and the advantages of using it [29]. It is even expected that the less expensive microwave chemistry equipment will gradually replace the use of flames, hotplates, and oil baths in the laboratory, making them obsolete so that they become the "Bunsen burners of the 21 st century" [10,30].

The Mingos group, initially at Oxford University, and then later at Imperial College, has been one of the pioneering research groups in this research area since the 1980s $[31,32]$. The research has been focused on the application of microwave dielectric heating in a range of chemical processes including the synthesis of superconducting ceramics [31] and other inorganic materials [33-41], the synthesis of organometallic compounds [42,43], solid-state reactions involving metal powders [44-48], and more recently heterogeneous catalytic reactions [49-55]. Advances have also been made in understanding dielectric heating behaviour $[24,29,50,52,56]$. Some of the early work has been reviewed previously [24,27,29]. The aim of the present paper is to review studies on the application of microwave dielectric heating in the environment-related heterogeneous catalytic reaction systems. The reactions investigated include the decomposition of hydrogen sulfide, the reduction of sulfur dioxide with methane, the reformation of methane by carbon dioxide, the hydrodesulfurization of thiophene, and the oxidative coupling of methane. The interaction of the microwave electromagnetic field with heterogeneous cata- 
lytic systems and its consequence for the microwave heating behaviour of catalysts has been examined. Based on the theoretical and experimental investigation, the effect/ mechanism of microwave dielectric heating on heterogeneous catalytic reaction systems has also been discussed.

\section{The interaction of microwave irradiation with heterogeneous catalytic systems}

\subsection{Microwave volumetric heating and selective heating}

A distinguishing feature of microwave heating is its volumetric nature whereby the microwave power is dissipated in a dielectric and the electromagnetic energy is converted directly to heat inside the sample. This is in contrast to conventional heating where heat enters the sample through its surface and is transferred towards the centre of the sample mainly by thermal conduction. Fig. 1 displays diagrammatically a qualitative comparison of the temperature gradient caused by these two heating methods. In general, the temperature inside the sample within a conventional furnace is lower than that at the surface because heat has to be transported from the surface to the interior. In the case of microwave heating, the radiation energy is dissipated within the sample more or less uniformly and a much higher heating rate can be obtained. As a result a significant temperature gradient can also exist but with the inside hotter than the surface.

The average power $P_{\text {abs }}$ dissipated in a dielectric of volume $V$ has been found to be related to the electric field $E$ and the material dielectric property by the equation $[50,57]$

$P_{\mathrm{abs}}=2 \pi f \varepsilon_{0} \varepsilon_{\mathrm{eff}}^{\prime \prime} E_{\mathrm{rms}}^{2} V$

where $f$ is the frequency of the radiation, $\varepsilon_{0}$ is the permittivity of free space, and $\varepsilon_{\text {eff }}^{\prime \prime}$ is the complex component of the relative permittivity of the dielectric, also known as the effective relative dielectric loss factor, and $E_{\mathrm{rms}}$ is the root mean square of the electric field $E$.

Eq. (1) represents the relation between the volumetric absorption of microwave power and the electromagnetic field for a given dielectric. However, in a solid material microwaves only penetrate a limited distance below the surface and this is represented by the penetration depth

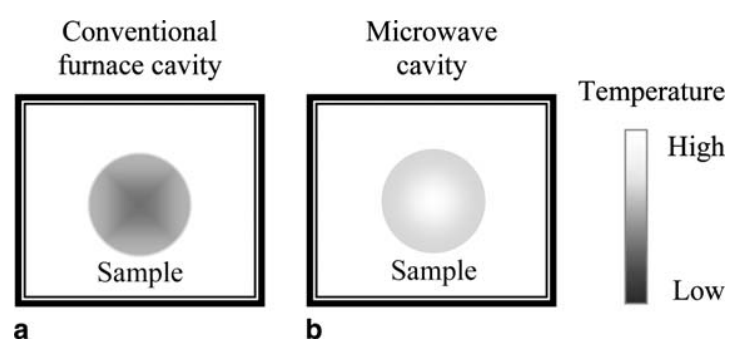

Fig. 1. Qualitative comparison of temperature gradient within samples heated by (a) conventional furnace heating and (b) microwave dielectric heating.
$D_{\mathrm{p}}$, which is often expressed as the depth where the microwave power drops to $1 / e(\approx 36.8 \%)$

$D_{\mathrm{p}}=\frac{\lambda_{0}}{2 \pi} \cdot \frac{\sqrt{\varepsilon^{\prime}}}{\varepsilon^{\prime \prime}}$

where $\lambda_{0}$ is the wavelength of the microwave radiation, $\varepsilon^{\prime}$ is the dielectric constant which describes the ability of a molecule to be polarized by the electric field, and $\varepsilon^{\prime \prime}$ is the dielectric loss which measures the efficiency to convert the electromagnetic radiation into heat.

It can be seen from both Eqs. (1) and (2) that the amount of microwave power absorbed by the dielectric is dependent not only on the electromagnetic field applied but also on the dielectric property of the material heated. In a simple way, the ratio of the dielectric loss and the dielectric constant is commonly used to measure the ability of a material to convert microwave radiation into heat energy at a given frequency and temperature, and this is referred to as the loss tangent

$\tan \delta=\varepsilon^{\prime \prime} / \varepsilon^{\prime}$

This suggests that under the same microwave heating conditions some materials are more capable than others of absorbing the microwave radiation energy because of their higher dielectric loss property; this is sometimes referred to as being more "lossy". In a heterogeneous catalytic system, for instance, the loss tangent of the solid catalyst is much higher (2-3 orders of magnitude) than that of the reactant gas and quartz reactor. As a result most of the power is absorbed by the catalyst whilst the reactant gas and quartz reactor can often reasonably be regarded as microwave transparent.

\subsection{Temperature and frequency dependency of dielectric properties of catalysts}

Based on the discussion above, it is understood that in microwave heating systems the dielectric property of the material heated controls the power that can be dissipated in a given material volume. Furthermore, it has been found that these parameters are both temperature and radiation frequency dependent [57]. Some effort has been made to quantify the effects of temperature and microwave frequency on dielectric properties $[52,58]$ in view of the fact that few data are available on the temperature variation of dielectric properties, particularly for heterogeneous catalysts in an elevated temperature range.

By using a cylindrical copper cavity the dielectric property of two $(30 \mathrm{wt} \%) \mathrm{MoS}_{2} / \gamma-\mathrm{Al}_{2} \mathrm{O}_{3}$ catalysts (one impregnated and the other mechanically mixed), and one impregnated $(8 \mathrm{wt} \%) \mathrm{Pt} /(20 \mathrm{wt} \%) \mathrm{CeO}_{2} / \gamma-\mathrm{Al}_{2} \mathrm{O}_{3}$ catalyst have been measured at elevated temperature ranging from 200 to $800^{\circ} \mathrm{C}$ at frequencies of $0.615,1.413,2.216,3.020$ and $3.825 \mathrm{GHz}$. The dielectric property of the support and bulk $\mathrm{MoS}_{2}$ was also measured under the same conditions. The measurements showed that both the dielectric constant and the dielectric loss increased with increasing 


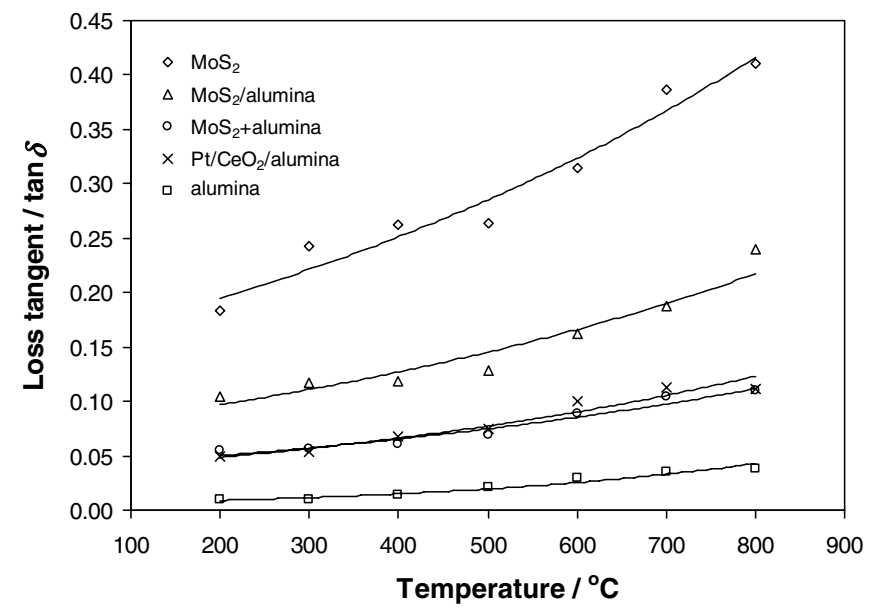

Fig. 2. Loss tangent of different samples as a function of temperature at frequency of $2.216 \mathrm{GHz}$. ( $\mathrm{MoS}_{2} /$ alumina and $\mathrm{Pt} / \mathrm{CeO}_{2} /$ alumina were impregnated catalysts whilst catalyst $\mathrm{MoS}_{2}+$ alumina was made by a mechanically mixing method $[51,52]$.)

temperature. Fig. 2 shows a typical trend of the temperature dependency of the dielectric loss of the catalysts. Data for both catalyst supported on $\gamma-\mathrm{Al}_{2} \mathrm{O}_{3}$ and for bulk $\mathrm{MoS}_{2}$ are also included for comparison. Based on these measurements, a model for the energy dissipation factor or loss tangent as a function of temperature has been proposed [52]

$\tan \delta=k_{\mathrm{A}}+k_{\mathrm{M}} \exp \left(-\frac{E_{\mathrm{a}}}{R T}\right)$

where the constants $k_{\mathrm{A}}$ and $k_{\mathrm{M}}$ are measures of the contribution made by microwave absorbers bound in deep and shallow potential wells, respectively, and $E_{\mathrm{a}}$ is the activation energy required to cause the interstitial atoms or vacancies in the material to become mobile.

It was also demonstrated that the same generic frequency dependence existed for the dielectric constant $\varepsilon^{\prime}$. It should be noted that the dielectric constant decreased with increasing frequency in the measured frequency range, whereas the frequency dependence of the dielectric loss factor $\varepsilon^{\prime \prime}$ varied with the material measured and this variation was found to be relatively insignificant.

\subsection{Characterization of microwave dielectric heating for heterogeneous catalytic systems}

It has been demonstrated that the power absorbed by a dielectric is determined by a combination of the electromagnetic filed applied, the volume of the sample and the dielectric property, which is expressed in Eq. (1). The power absorbed is used to raise temperature but this is counteracted by heat being partially lost to the surrounding environment. With reasonable approximations, a simplified model can be used to describe the rate of rise of temperature during microwave heating [50].

$C_{\mathrm{p}}\left(\frac{\mathrm{d} T_{\mathrm{s}}}{\mathrm{d} t}\right)=2 \pi f \varepsilon_{0} \varepsilon_{\mathrm{eff}}^{\prime \prime} E_{\mathrm{rms}}^{2} V-\alpha\left(T_{\mathrm{s}}-T_{0}\right)$ where $C_{\mathrm{p}}$ is the heat capacity of the sample, $\alpha$ is the heat transfer coefficient. The heat loss is caused mainly by conduction and is proportional to the temperature gradient between the sample at temperature $T_{\mathrm{s}}$ and the ambient temperature $T_{0}$. Therefore the temperature at a steadystate can be given by the equation

$2 \pi f \varepsilon_{0} \varepsilon_{\mathrm{eff}}^{\prime \prime} E_{\mathrm{rms}}^{2} V=\alpha\left(T_{\mathrm{s}}-T_{0}\right)$

However, in many instances the relative dielectric loss factor shows a strong variation with temperature as indicated in Fig. 2 and this can sometimes lead to a thermal "runaway" in which the temperature continues to rise uncontrollably. The achievement of a steady temperature then depends upon whether there are solutions to Eq. (6). In general, analytical solutions of this equation are not possible but solutions can be found by plotting the two terms separately and observing the crossover points. This is illustrated in Fig. 3, which shows a diagram of absorbed microwave power, $P_{\text {abs }}$, versus temperature for three different fixed values of the input power, $P_{\text {in }}$. The rate of heat loss from the catalyst is represented by the straight line, the assumption being that the rate of loss of heat is proportional to the temperature difference.

It can be seen that when the input power is small $\left(P_{1}\right)$ the exponential curve crosses the straight line at two points, A and B. If the initial temperature is $T_{0}$, the sample will heat up to $T_{\mathrm{A}}$, where the rate of heat loss will balance the heat input. If the sample temperature happens to rise above $T_{\mathrm{A}}$, perhaps because of a temporary surge in the input power or a fluctuation in, the rate of heat loss will exceed the rate of heat generation and the sample will cool back down to $T_{\mathrm{A}}$. Consequently $T_{\mathrm{A}}$ is a stable temperature. On the other hand, the second cross-over point represents an unstable situation in which any small fluctuation will lead to the temperature either falling or rising uncontrollably.

A different situation applies when the power input in Fig. 3 is raised to $P_{2}$ where the exponential curve lies above the straight line and the sample temperature will keep on rising until the sample melts, decomposes or electrical

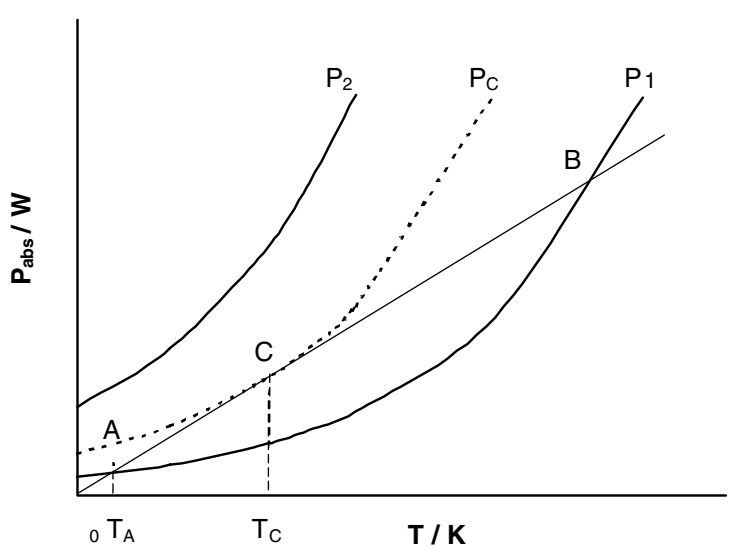

Fig. 3. Power-temperature graph for thermal breakdown. (The straight line is the heat carried away from the sample, and the curves represent the heat dissipated in the sample for various values of applied power.) 


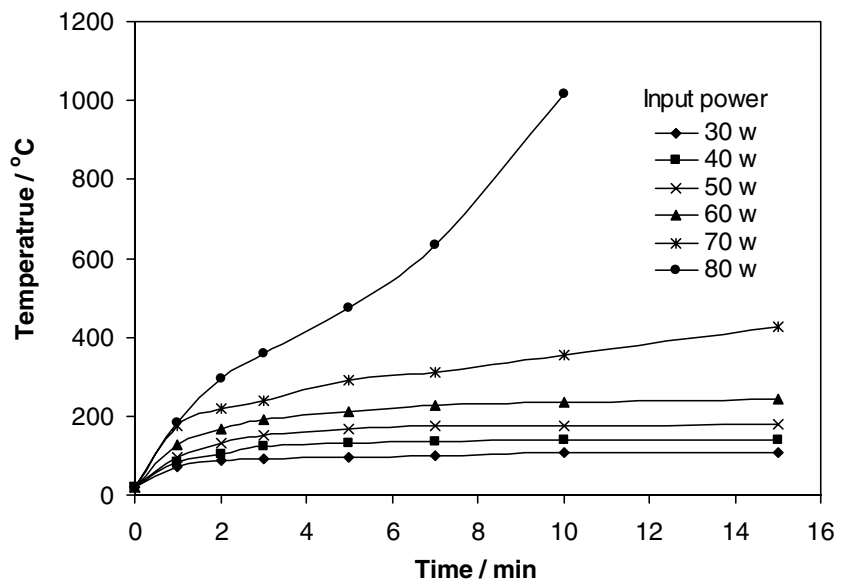

Fig. 4. Temperature vs. time with microwave heating over $(8 \mathrm{wt} \%) \mathrm{MoS}_{2} /$ $\gamma-\mathrm{Al}_{2} \mathrm{O}_{3}$ at different input power levels.

breakdown occurs. There is a critical power input, $P_{\mathrm{c}}$, and a critical temperature, $T_{\mathrm{c}}$, where the exponential curve just touches the straight line. For input powers less than $P_{\mathrm{c}}$ the sample should heat up to a steady temperature but for input powers above $P_{\mathrm{c}}$ the temperature will continue to rise uncontrollably.

This theoretical analysis has been verified by experiment. Fig. 4 shows an example of experimental results when an impregnated catalyst, $(8 \mathrm{wt} \%) \mathrm{MoS}_{2}$ supported on $\gamma-\mathrm{Al}_{2} \mathrm{O}_{3}$ was heated at different microwave power inputs. It can be seen that at low input power levels the system was able to reach a steady-state where its temperature was retained at a constant level. At higher power input levels there appeared to be a critical input power level above which the fraction of the power that was absorbed increased markedly with rising temperature and resulted in a thermal "runaway". The critical input power levels were found to be about $70 \mathrm{~W}$ for the $\mathrm{MoS}_{2} / \gamma-\mathrm{Al}_{2} \mathrm{O}_{3}$ catalyst under these conditions.

In summary, the theoretical analysis and experimental measurements are in good agreement, and give a good understanding of microwave dielectric heating in a heterogeneous catalytic system. This information may prove useful in reactor design and the optimization of system operation.

\section{Applications of microwave dielectric heating in environment-related heterogeneous catalytic reactions}

\subsection{The decomposition of hydrogen sulfide}

The decomposition of hydrogen sulfide into hydrogen and sulfur is commercially important for the coal and petrochemical industry [59]; the emission of hydrogen sulfide into the atmosphere causes damage to the environment since it is a strong acid pollutant; it may also damage metallic equipment due to corrosion. Along with the development of a variety of methods for the decomposition of hydrogen sulfide [60-64], the catalytic decomposition of hydrogen sulfide, assisted by microwave dielectric heating, has been investigated [49]. The basic reaction is given by

$$
\mathrm{H}_{2} \mathrm{~S} \rightleftarrows \mathrm{H}_{2}+1 / 2 \mathrm{~S}_{2} \quad H^{0}=84.8 \mathrm{~kJ} \mathrm{~mol}^{-1}
$$

In the microwave-assisted reaction system, the reactions were performed under continuous flow conditions using tubular quartz reactors. The temperature in the microwave cavity was monitored using an optical fibre thermometer. The catalyst used was either an impregnated molybdenum sulfide on $\gamma$-alumina or a mechanically mixed sample of molybdenum sulfide on $\gamma$-alumina. A comparison of the conversion efficiency is displayed in Fig. 5 for the decomposition of $\mathrm{H}_{2} \mathrm{~S}$ under microwave and conventional thermal conditions in the temperature range $400-800{ }^{\circ} \mathrm{C}$ for both the impregnated catalyst and the mechanical mixture of $\mathrm{MoS}_{2}$ and $\gamma$-alumina (both $30 \%$ by weight $\mathrm{MoS}_{2}$ on $\gamma$ alumina). The calculated equilibrium conversion efficiencies are also illustrated for comparison.

It can be seen that the results obtained under conventional heating conditions were in good agreement with the equilibrium data. However, the $\mathrm{H}_{2} \mathrm{~S}$ conversion under microwave conditions was much higher than those obtained with conventional heating at the same nominal temperature. Most surprisingly, the $\mathrm{H}_{2} \mathrm{~S}$ conversions were higher than the equilibrium $\mathrm{H}_{2} \mathrm{~S}$ conversions calculated from thermodynamic data. It was also interesting to note that the conversion of $\mathrm{H}_{2} \mathrm{~S}$ with the mechanically mixed catalyst was much higher than that obtained with the impregnated catalyst at the same temperature.

The "apparent" shifts in equilibrium constant for the reactions observed suggest that the reaction was occurring at a considerably higher temperature at some sites in the catalyst bed compared to the average temperature measured. This could be the result of microwave volumetric heating in which the temperature inside the catalyst tends to be generally higher than that at the surface, but there is considerable evidence for the existence of localized

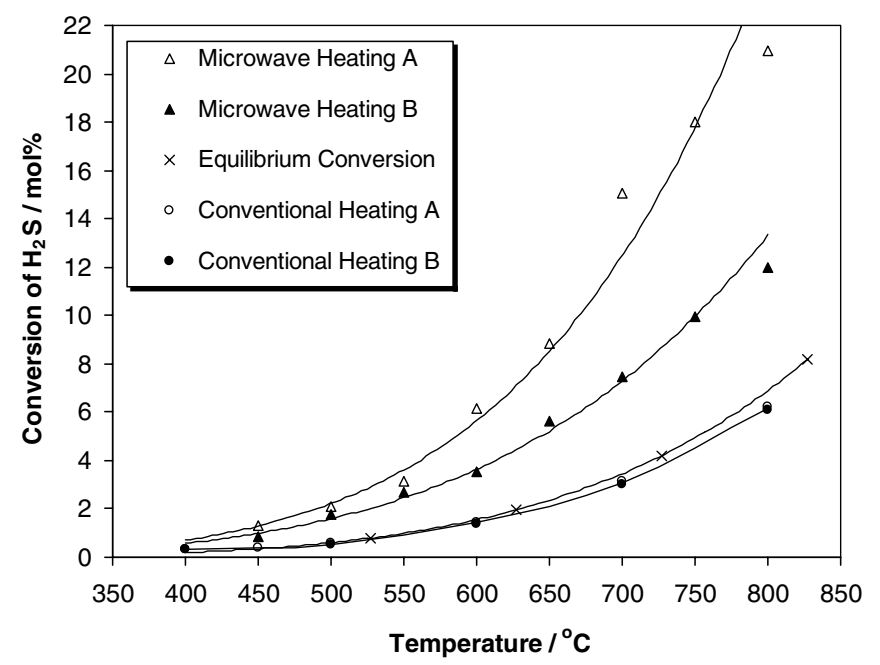

Fig. 5. $\mathrm{H}_{2} \mathrm{~S}$ conversion as a function of temperature over mechanically mixed catalyst $\mathrm{A}$ and impregnated catalyst $\mathrm{B}$. 
"hot spots" $[65,66]$. These high temperature sites can arise either from microwave selective heating of materials with variable dielectric properties or by an uneven distribution of electromagnetic field strength [50].

Furthermore, the presence of hot-spots could also explain the higher efficiency produced by the mechanically mixed catalyst compared to the impregnated one. With conventional heating the impregnated catalyst, which has a better dispersion of catalyst particles and a higher surface area, generally gives a better result than the mechanically mixed catalyst. However, under microwave heating conditions the poorly dispersed mechanical mixture was more likely to accentuate the hot-spot phenomenon, either because there was a higher concentration of hot-spots, or because the hot-spots had a higher temperature.

\subsection{Reduction of sulfur dioxide with methane}

Sulfur dioxide is another important pollutant of the environment and it is generally accepted to be the main precursor to acid rain. For this reason the removal of sulfur dioxide has attracted a lot of attention [67-73]. The catalytic reduction of sulfur dioxide with methane to form carbon dioxide and sulfur has also been studied over $\mathrm{MoS}_{2} /$ $\mathrm{Al}_{2} \mathrm{O}_{3}$ catalysts under microwave heating conditions [51]. The principal reaction for the reduction of $\mathrm{SO}_{2}$ by $\mathrm{CH}_{4}$ can be represented as:

$$
2 \mathrm{SO}_{2(\mathrm{~g})}+\mathrm{CH}_{4(\mathrm{~g})}=2[\mathrm{~S}]_{(\mathrm{g})}+\mathrm{CO}_{2(\mathrm{~g})}+2 \mathrm{H}_{2} \mathrm{O}_{(\mathrm{g})}
$$

The same catalysts used for the $\mathrm{H}_{2} \mathrm{~S}$ decomposition reaction described above have been used for the $\mathrm{SO}_{2}$ reduction with $\mathrm{CH}_{4}$. Fig. 6 compares the $\mathrm{SO}_{2}$ and $\mathrm{CH}_{4}$ conversion efficiencies as a function of temperature for conventional and microwave dielectric heating with a mechanically mixed catalyst (30 wt $\% \mathrm{MoS}_{2}+\gamma-\mathrm{Al}_{2} \mathrm{O}_{3}$ ) at an $\mathrm{SO}_{2} / \mathrm{CH}_{4}$ molar feed ratio of 2 . It shows that there is a significant difference in both $\mathrm{SO}_{2}$ and $\mathrm{CH}_{4}$ conversions between the two heating methods employed. For conversions of $\mathrm{SO}_{2}$ or $\mathrm{CH}_{4}$

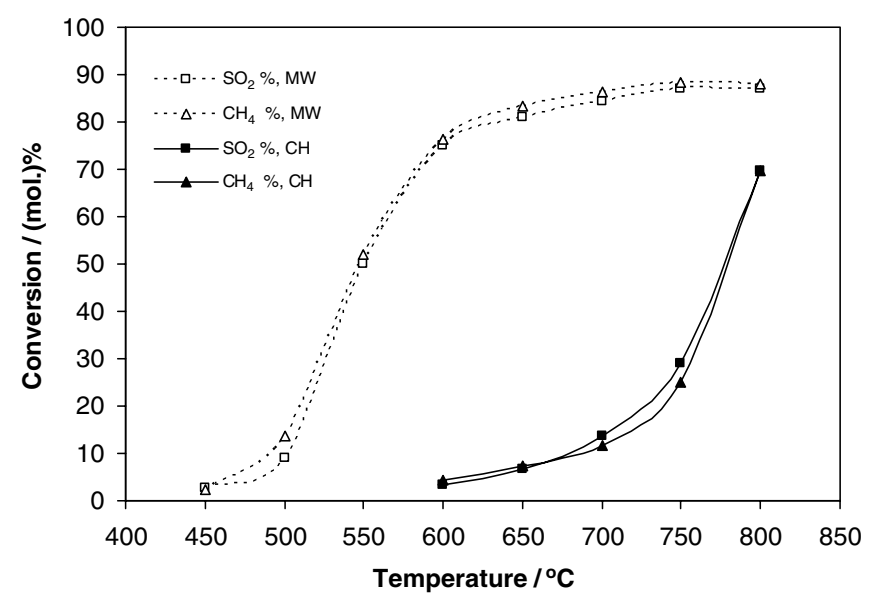

Fig. 6. $\mathrm{SO}_{2}$ and $\mathrm{CH}_{4}$ conversions as a function of temperature over mechanically mixed catalyst ((30 wt $\left.\%) \mathrm{MoS}_{2}+\gamma-\mathrm{Al}_{2} \mathrm{O}_{3}\right)$ using either microwave heating $(\mathrm{MW})$ or conventional heating $(\mathrm{CH})$ method. between $10 \%$ and $70 \%$, the same percentage conversion can be achieved with microwave heating at temperatures which are about $200{ }^{\circ} \mathrm{C}$ lower than exactly the those required when conventional heating was used. This temperature difference is of the same order of magnitude as that found for the decomposition of $\mathrm{H}_{2} \mathrm{~S}$ with microwave and conventional heating. This is again indicative that some regions of the catalyst have reached temperatures which are $\approx 200{ }^{\circ} \mathrm{C}$ in excess of the measured average temperature.

The comparison of the catalysts made by different procedures also shows that the mechanically mixed catalyst is apparently more active than the impregnated catalyst under microwave heating conditions, in keeping with the conclusions of a previous study of the catalytic decomposition of $\mathrm{H}_{2} \mathrm{~S}$ over $\mathrm{MoS}_{2}$ catalysts [49]. All the observations show the very likely existence of hot-spots and this is further supported by an examination of the catalyst.

\subsection{Reforming of methane with carbon dioxide}

The carbon dioxide reforming of methane has been of interest for a long time, dating back as far as the 1920s [74], but it is only in recent years that interest in this reaction has increased rapidly for both environmental and commercial reasons [75-83]. Based on the observation that microwave dielectric heating can accelerate the reaction rate in general and even result in "apparent" shifts in the equilibrium constant of reactions, this advanced heating method has been employed for the catalytic reforming of methane with carbon dioxide over Pt catalysts [54]. This reaction can be represented as:

$$
\mathrm{CH}_{4}+\mathrm{CO}_{2}=2 \mathrm{CO}+2 \mathrm{H}_{2} \quad H^{0}=247 \mathrm{~kJ} \mathrm{~mol}^{-1}
$$

The conversion of $\mathrm{CH}_{4}$ as a function of temperature is shown in Fig. 7 for both microwave and conventional heating using a $\mathrm{Pt}(8 \%) / \mathrm{CeO}_{2}(20 \%) / \gamma-\mathrm{Al}_{2} \mathrm{O}_{3}$ catalyst and a feed molar ratio $\left(\mathrm{CO}_{2} / \mathrm{CH}_{4}\right)$ of 1.0:1.0. The equilibrium conversion of $\mathrm{CH}_{4}$ is also plotted in the figure, where two reac-

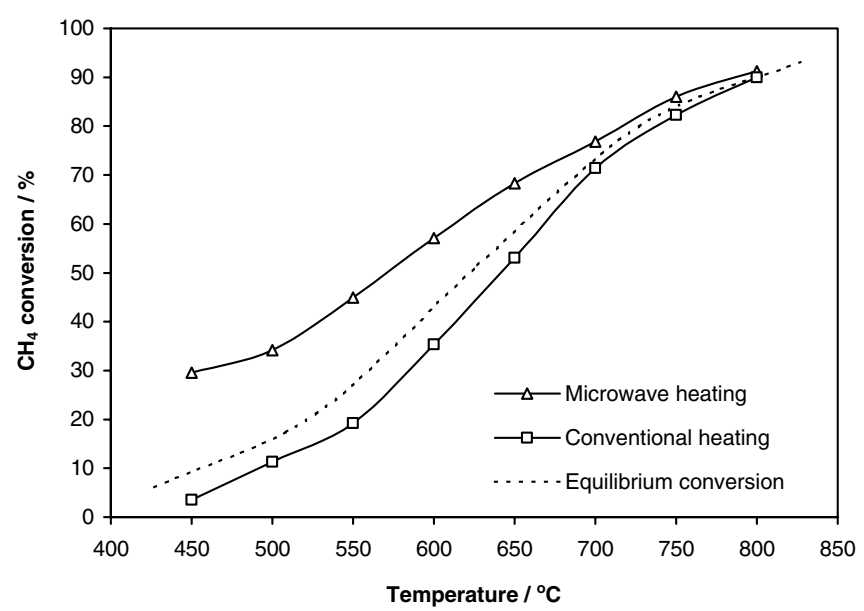

Fig. 7. $\mathrm{CO}_{2}$ and $\mathrm{CH}_{4}$ conversions as a function of temperature over catalyst $\mathrm{Pt}(8 \%) / \mathrm{CeO}_{2}(20 \%) / \gamma-\mathrm{Al}_{2} \mathrm{O}_{3}$. 


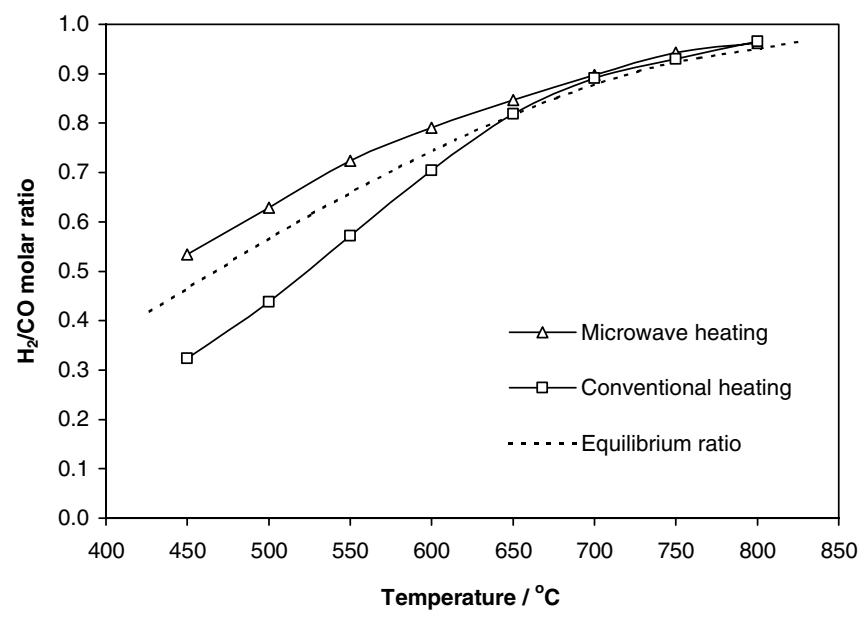

Fig. 8. Products selectivity as a function of temperature over catalyst $\mathrm{Pt}(8 \%) / \mathrm{CeO}_{2}(20 \%) / \gamma-\mathrm{Al}_{2} \mathrm{O}_{3}$.

tions may be going on, namely the carbon dioxide reforming of methane, which is the main reaction, and the reverse water-gas shift reaction, which is a secondary reaction. It can be seen the percentage conversion of $\mathrm{CH}_{4}$ increased with temperature and, for microwave heating, was greater than the equilibrium conversion at the same temperature. As the temperature was raised the percentage conversion using microwave heating was found to get closer to that calculated for equilibrium, and the two conversions finally merged at the highest temperatures used. This may result from the very high percentage conversion observed at high temperature, which exceeded $80 \%$.

Apart from the increased conversion observed under microwave conditions, the effect on the production selectivity was also found to be significant, particularly when the temperature was below $700{ }^{\circ} \mathrm{C}$ (Fig. 8). As the microwave effect on the conversion was attributed to the formation of hot-spots, its effect on the $\mathrm{H}_{2} / \mathrm{CO}$ ratio should be similar to that observed with the thermal temperature effect. When microwave heating was employed the reaction could occur at a higher temperature than that measured. According to the thermodynamic analysis for the reaction systems, an increase in temperature is more favourable to the main reaction, which produces hydrogen and carbon monoxide. Thus, using microwave heating, a higher $\mathrm{H}_{2} / \mathrm{CO}$ ratio could be reached than the equilibrium value predicted for the measured temperature level. At temperatures above $700{ }^{\circ} \mathrm{C}$, the microwave hot-spot effect appeared to be less although the two curves must come together at very high temperature when the $\mathrm{H}_{2} / \mathrm{CO}$ ratios from microwave and conventional heating must both approach unity.

\subsection{Hydrodesulfurization (HDS) of thiophene - an exothermic reaction}

Thiophene is representative of the organosulfur compounds found in crude oil. Its presence is undesirable, not only because it introduces technical problems into oil processing and application systems, but also because of growing social concern regarding environmental constraints. Hydrodesulfurization (HDS) of thiophene has long been one of the major catalytic operations to reduce thiophene in the petroleum industry, and has already been put to practical use commercially for many years [84], although current research into the process is still active and related to the need for efficient upgrading of crude oil fractions [85-87]. The hydrodesulfurization of thiophene, where thiophene reacts with hydrogen to produce butane and hydrogen sulfide, is represented by

$$
\mathrm{C}_{4} \mathrm{H}_{4} \mathrm{~S}+4 \mathrm{H}_{2} \rightleftarrows \mathrm{C}_{4} \mathrm{H}_{10}+\mathrm{H}_{2} \mathrm{~S} \quad H^{0}=-262.6 \mathrm{~kJ} \mathrm{~mol}^{-1}
$$

This reaction has been selected for study by microwave heating not only because of its similarity to the catalytic reaction systems described above, but more importantly because it is relatively strongly exothermic [88].

In previous studies on the application of microwaves in heterogeneous catalysis, all the reactions studied, including the decomposition of $\mathrm{H}_{2} \mathrm{~S}$, reduction of $\mathrm{SO}_{2}$ with $\mathrm{CH}_{4}$, and the $\mathrm{CO}_{2}$ reforming of $\mathrm{CH}_{4}$, have been endothermic so that the proposed hot-spots could result not only in an acceleration in reaction rates but also an apparent shift in equilibrium, giving a higher reactant conversion than that expected at the observed temperature. In this strongly exothermic HDS reaction, according to the arguments developed above, the equilibrium conversion will decrease as the temperature is increased. Based on the "hot-spots" assumption the reaction temperature at some points should be higher than that measured, which has the consequence that [53]:

(a) the rate of the forward reaction should be increased; but

(b) the maximum attainable conversion should be decreased provided that the reaction rate is high enough to reach the equilibrium conversion.

The results, shown in Fig. 9, indicate that the variation of the conversion of thiophene with temperature occurred

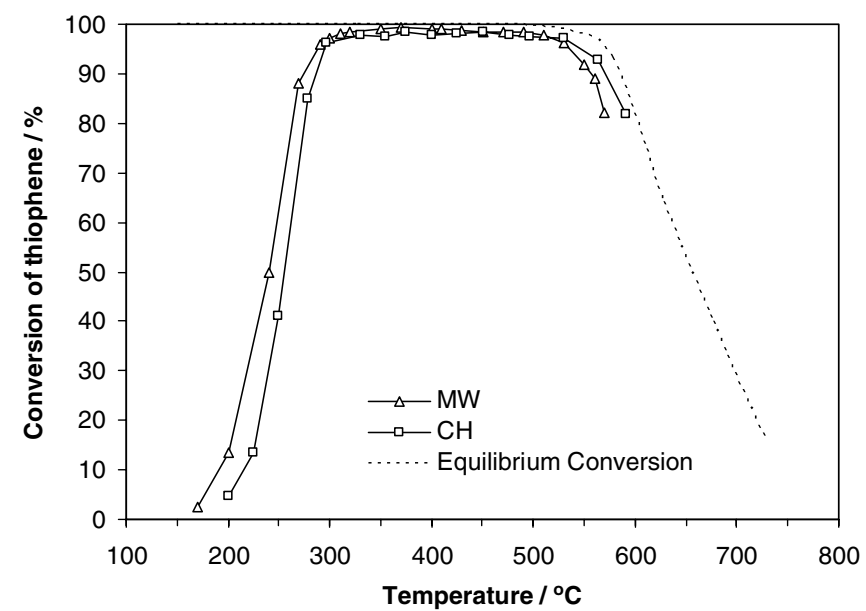

Fig. 9. Conversion of thiophene as a function of temperature. 
in three stages, under both microwave and conventional heating.

(i) The conversion increased markedly with temperature up to $300^{\circ} \mathrm{C}$.

(ii) The conversion then reached a very high level, approaching the equilibrium conversion, in the temperature range of $300-500{ }^{\circ} \mathrm{C}$.

(iii) The conversion declined after the temperature was increased above $500{ }^{\circ} \mathrm{C}$.

It is worthwhile noting the difference in thiophene conversions obtained using the two heating methods. In the first stage, the reaction rate under microwave conditions was higher than that with conventional heating. This observation indicated that the reaction temperature was higher than that measured while the reaction was under kinetic control. In the second stage, the thiophene conversion approached the equilibrium value at a very high level (close to $100 \%$ ) so there was no significant difference in thiophene conversions obtained with different heating methods. This result also showed a high catalytic activity of the commercial catalyst BP-C2634. In the high temperature range, i.e., the third stage, when the temperature was increased further, the conversion decreased, being limited by the equilibrium conversion. It is interesting to note that in this higher temperature range, the thiophene conversion under microwave heating diverged more from the theoretical equilibrium data. By contrast the thiophene conversion with conventional heating was close to equilibrium. Based on the hot-spot assumption, the reaction temperature was higher under microwave conditions than that measured. Thus, for this exothermic reaction - hydrodesulfurization of thiophene, the hot-spots could increase the reaction rate, but they could also "shift" the equilibrium in a less favourable direction, because the equilibrium constant at the temperature of the hot-spots was lower than that at the apparent measured temperature in the bulk catalyst.

However, at higher temperatures $\left(>600^{\circ} \mathrm{C}\right)$ the thermocracking of thiophene occurred which resulted in a change in the product distribution and $\mathrm{C}_{1}, \mathrm{C}_{2}$ hydrocarbons were produced. So, it was difficult to study the HDS reaction at higher temperatures under atmospheric pressure.

\subsection{Oxidative coupling of methane to higher hydrocarbons}

Most of the early work on the application of microwaves in heterogeneous catalysis had been focused on the oxidative coupling of methane, aiming to produce higher hydrocarbons [89-91]. A study of the oxidative coupling of methane using both conventional and microwave heating was carried out by Wan et al. in the early 1990s [89], initially using pulsed-microwave radiation to study the reaction of methane in the absence of oxygen. The reaction was performed over a series of nickel catalysts, and the products produced appeared to be a function of both the catalyst used and the power and frequency of the micro- wave pulses. In their study, a $\mathrm{Ni}-\mathrm{SiO}_{2}$ catalyst was reported to produce $93 \%$ acetylene, whereas a $\mathrm{Ni}(1 \mu \mathrm{m}) /$ $\mathrm{Ni}(100$ mesh) catalyst under the same conditions of irradiation produced no acetylene but $83 \%$ ethylene and $8.5 \%$ ethane. By altering the microwave pulse cycle, it was found that a complex mixture of hydrocarbons, up to and including $\mathrm{C}_{6}$ and $\mathrm{C}_{7}$ aromatics, was produced. In a study conducted by Chen et al. [66] on the microwave effects on the oxidative coupling of methane over rare-earth oxide catalysts, a change in both the product selectivity and the product species formed was also shown when compared to the conventionally heated reaction.

Bond et al. [65] have tested a number of basic oxides for the reactions and confirmed that when microwave heating is used in place of conventional heating $\mathrm{C}_{2}$ formation occurs at much lower temperatures with increased selectivity. This significant reduction in reaction temperature exceeds all attempts that have been made so far to improve catalyst activity when conventional heating is employed. Additionally, it has been found that microwave radiation resulted in an increased ratio of ethylene to ethane, which is desirable, and also an increased selectivity of $\mathrm{CO}$ at the expense of $\mathrm{CO}_{2}$. This is important because $\mathrm{CO}$ is more useful than $\mathrm{CO}_{2}$. Roussy et al. [90] have also found an enhanced selectivity for higher hydrocarbons in oxidative coupling of methane over microwave-irradiated catalysts.

However, for oxidative coupling occurring in the presence of oxygen over alumina supported $\mathrm{La}_{2} \mathrm{O}_{3} / \mathrm{CeO}_{2}$ catalysts, no significant difference was found between the temperatures at which products were first observed using the two heating methods, nor was there any significant difference in selectivities [55]. In this case, microwave heating showed no significant effects that could make it an advantageous method of heating. In contrast, when methane was converted into $\mathrm{C}_{2}$ hydrocarbons in the absence of oxygen, microwave heating was found to have a dramatic effect on the reaction, with products appearing at measured temperatures about $250{ }^{\circ} \mathrm{C}$ lower than those observed with conventional heating. Fig. 10 shows the comparison of the conversion of methane by using microwave and conventional heating methods when oxygen was absent.

In an earlier study [56], ethane production was seen at temperatures as low as $600^{\circ} \mathrm{C}$, some $250{ }^{\circ} \mathrm{C}$ below the temperature at which ethane was first detected under conventional heating. As the temperature was raised further, the ethylene signal became dominant with a $14.7 \%$ conversion at temperatures between 850 and $900{ }^{\circ} \mathrm{C}$. In contrast to the run using conventional heating, ethane only appeared when the temperature of the reaction exceeded $850^{\circ} \mathrm{C}$, followed by ethylene production between 900 and $1000^{\circ} \mathrm{C}$. Similar results have also been obtained by other researchers [91-93] in a study of the oligomerization of methane to higher hydrocarbons using microwave heating. In their studies, Marun et al. [91] have observed arc formation and discharges produced by the catalyst. Ethane was obtained as the major product at the beginning of the reaction. However, when arc formation was noticeable, signif- 


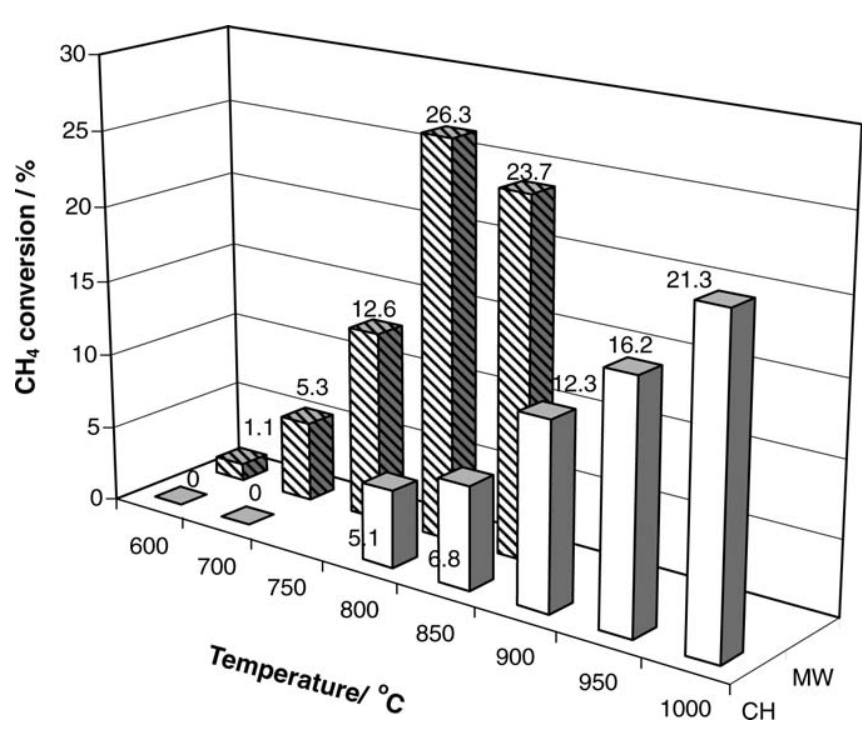

Fig. 10. Conversion of $\mathrm{CH}_{4}$ as a function of temperature in absence of $\mathrm{O}_{2}$ using both microwave (MW) and conventional heating $(\mathrm{CH})$.

icant selectivity for ethylene and acetylene was obtained. Acetylene production was then seen to increase at high microwave power when arcing was present. These results are in accord with earlier data for the oligomerization of methane via microwave plasmas [94]. Thus, the occurrence of a $\mathrm{CH}_{4}$ plasma with arcing can lead to the establishment of a high temperature gradient within the catalyst. It was also indicative that the reaction in the absence of oxygen occurred primarily in the gas phase and it was the localized heating of the methane that was responsible for the increased reaction rate.

\section{The effects of microwave dielectric heating on heterogeneous catalysis}

There have been numerous reports that the rate of some chemical reactions can be increased and the product selectivity changed when microwave heating is used [51,95-100]. There has been some debate about whether this effect is simply a thermal one, due to the higher temperatures attained at hot-spots, or whether they are caused by nonthermal interactions between the substrate and the microwave radiation [53,101-104].

In some early studies of microwave-assisted catalysis results were obtained which were difficult to explain in terms of non-uniform heating of the catalyst and it was suggested that microwave irradiation might interact directly with the reactants to cause an enhancement of the reaction rate [105-107]. However, further studies, both theoretical and experimental, have conclusively demonstrated that specific athermal effects are implausible $[22,108-110]$. Stuerga and Gaillard $[108,109]$ analyzed the interaction between microwave electromagnetic fields and chemical structures and finally concluded that the microwave field cannot have any significant molecular or athermal effect on such systems. Hajek [110] carried out an experimental investigation into microwave assisted catalytic reactions from the point of view of the initiation of chemical reactions and concluded that non-thermal effects did not occur in either homogeneous or heterogeneous reactions.

Thus, enhancements of the reaction rate and product selectivity under microwave conditions must be attributed to thermal effects which may result because of differences between the real reaction temperature at the reaction sites and the observed average temperature. However, in a gas/solid heterogeneous catalytic system, this temperature difference may exist in different forms within the heterogeneous system, and there are three cases to be considered and discussed below.

(i) The catalyst particle temperature and/or catalyst support temperature are/is different from the gas temperature.

(ii) The catalyst particle temperature is higher than the catalyst support temperature.

(iii) The temperature of the spatial hot spot within the catalyst bed is different from the average temperature of the catalyst bed.

\subsection{Temperature difference between catalyst and reactant}

Based on their experimental observations of the oxidative coupling of methane under microwave irradiation, Roussy et al. have [111] have proposed that the gas must have been colder than the catalyst bed because this was the only way in which they could interpret the enhancement in the selective formation of higher hydrocarbons. The effect of the temperature difference on reactions was further investigated by varying the inlet gas temperature [53].

Fig. 11 compares the results of $\mathrm{H}_{2} \mathrm{~S}$ conversion with and without the reactant gas being pre-heated to $230{ }^{\circ} \mathrm{C}$ before

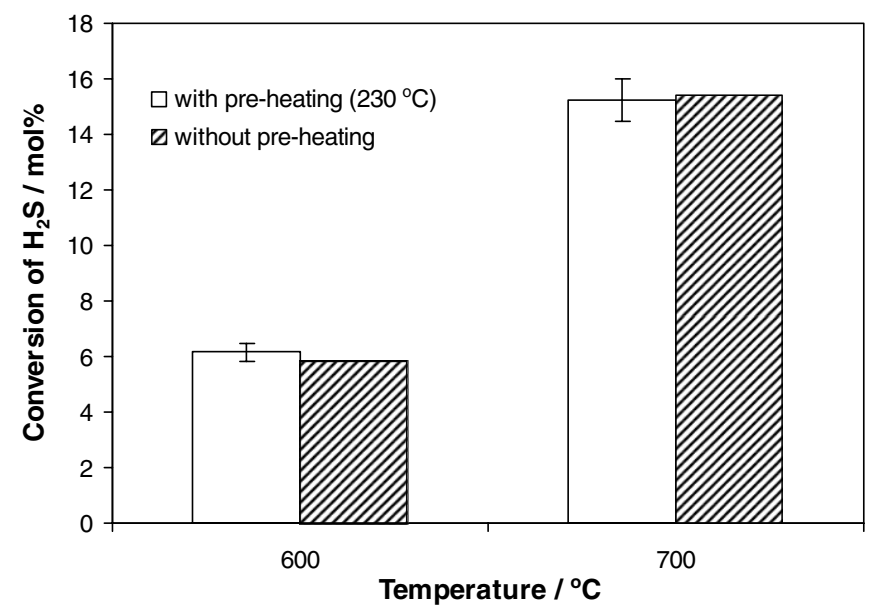

Fig. 11. Effects of pre-heating of inlet reactant gas on the decomposition of $\mathrm{H}_{2} \mathrm{~S}$. 
it reached the reactor. Runs were carried out at reaction temperatures of 600 and $700{ }^{\circ} \mathrm{C}$ and it can be seen that there was no significant difference in $\mathrm{H}_{2} \mathrm{~S}$ conversion between the runs with reactant gas pre-heating and those without. This suggests that varying the gas-phase temperature does not change the temperature gradient, or affect the reaction rate.

\subsection{Temperature difference between catalyst particles and catalyst support}

Chemat et al. [112] investigated heterogeneous catalytic reactions using a continuous microwave reactor and compared the results with those obtained by conventional heating. The increased reaction rate was attributed to selective heating of the catalyst particles, and the temperature of the reactive site was calculated to be $9-18{ }^{\circ} \mathrm{C}$ above the bulk temperature. Thomas [113] used heat transfer analysis to determine the extent of selective heating of metallic catalyst particles attached to a support and subjected to microwave radiation. He concluded that selective heating is possible provided the microwave fields have a high frequency and the catalyst beds are cooled by a gas at low pressure.

However, further theoretical analysis of the temperature difference between catalyst particles and their support shows that the temperature difference between a $\mathrm{MoS}_{2}$ particle and the alumina support must be very small [53].

A simplified model of heat transfer based on a $\mathrm{MoS}_{2}$ particle suspended in gas at $1 \mathrm{~atm}$ pressure inside a spherical $\gamma-\mathrm{Al}_{2} \mathrm{O}_{3}$ cavity was employed to estimate the temperature difference between $\mathrm{MoS}_{2}$ and its alumina support. The following approximations were made: (a) only heat loss from the $\mathrm{MoS}_{2}$ particle to the gas phase was considered so that, at the steady-state, the microwave energy absorbed by the $\mathrm{MoS}_{2}$ particle equals the heat lost to the gas-phase; (b) it is assumed that all the microwave energy is absorbed by $\mathrm{MoS}_{2}$, the amount of energy absorbed by the $\gamma-\mathrm{Al}_{2} \mathrm{O}_{3}$ support being insignificant. These assumptions represent the best opportunity for a temperature gradient to be sustained, as the heat conduction into the $\gamma-\mathrm{Al}_{2} \mathrm{O}_{3}$ support would lower the temperature gradient.

The catalyst used was $30 \%$ (wt) $\mathrm{MoS}_{2}$ supported on $\gamma$ $\mathrm{Al}_{2} \mathrm{O}_{3}$ and the weight of a typical sample was $0.50 \mathrm{~g}$, of which $0.15 \mathrm{~g}$ was $\mathrm{MoS}_{2}$. These samples absorbed about $60 \mathrm{~W}$ of microwave energy. Assuming that the $\mathrm{MoS}_{2}$ particles are spherical with a diameter of $2 \mu \mathrm{m}$, it was calculated that each particle absorbed about $8 \times 10^{-9} \mathrm{~W}$.

Calculation of heat loss. For a spherical $\mathrm{MoS}_{2}$ particle of radius $R_{1}$ in a spherical $\gamma-\mathrm{Al}_{2} \mathrm{O}_{3}$ cavity of radius $R_{2}$ the rate of heat transfer is given by the following formula, when the mean free path of the gas exceeds the particle size and $R_{2} \gg R_{1}[53,114]$

$Q=A \alpha\left[\frac{P}{(2 \pi M R T)^{1 / 2}}\right]\left[\left(C_{v}+\frac{1}{2} R_{1}\right)\left(T_{1}-T_{2}\right)\right]$ where $\alpha$ is the accommodation coefficient of the gas phase molecules at the surface of the particle, $P$ is the gas pressure, $M$ is molecular weight, $A$ is the particle surface area, and $T_{1}, T_{2}$ are the temperatures of the particle and the support wall, respectively. Using $\alpha=0.8$, and $C_{v}=$ $34.2 \mathrm{~J} \mathrm{~mol}^{-1} \mathrm{~K}^{-1}\left(\mathrm{H}_{2} \mathrm{~S}\right)$ the heat loss from a $\mathrm{MoS}_{2}$ particle is calculated to be about $1 \times 10^{-6} \times\left(T_{1}-T_{2}\right) \mathrm{J} \mathrm{s}^{-1}$.

Comparing this value with the heat generated by microwaves in each particle of $8 \times 10^{-9} \mathrm{~W},\left(T_{1}-T_{2}\right)$ is calculated to be $8 \times 10^{-3} \mathrm{~K}$. The temperature gradient in this limiting case is very small and the $\mathrm{MoS}_{2}$ particles are therefore very nearly in thermal equilibrium with the surrounding $\gamma-\mathrm{Al}_{2} \mathrm{O}_{3}$. For a platinum-air-alumina system, the temperature difference between the metallic Pt particle and its alumina support has also been calculated to be negligible, i.e., $1.1 \times 10^{-10} \mathrm{~K}[115]$.

Furthermore, the calculation shows that the diameter of the $\mathrm{MoS}_{2}$ particles would have to be of the order of $\mathrm{mm}$ in order to achieve a significant temperature difference. Thus, only hot-spots of this size can be maintained for significant times in the catalyst because of the rapid transfer of heat via the gas phase. For metallic catalysts attached to a support by means of microwave heating a similar conclusion has been drawn from heat transfer analysis [113].

\subsection{Spatial hot-spots within catalyst beds}

The existence of hot spots, or large temperature gradients, within a catalyst bed subject to microwave heating has been suggested by a number of researchers $[50,65,66]$. However, the discussion and analysis shown above have excluded there being a significant temperature difference between either the catalyst and the bulk gas or the catalyst particle and the support. Thus, hot-spots are very likely located within the catalyst bed, possibly, on a relatively large scale, which has been confirmed by the examination of the catalysts after microwave heating.

Changes in catalyst surface area. A significant reduction in surface area has been noticed for the catalyst used in the reaction of sulfur dioxide with methane over $\mathrm{MoS}_{2}$ catalysts [51]. It was found that the surface areas of the catalyst were much smaller after reaction when microwave heating was used than they were after conventional heating. For example, the surface area of catalyst MC-2 was $57 \%$ of the original area after conventional heating but only $17 \%$ of the original area after microwave heating. This indicated that microwave heating caused a considerable reorganization of the catalyst structure.

$X$-ray diffraction (XRD) measurements. $\mathrm{MoS}_{2} / \gamma-\mathrm{Al}_{2} \mathrm{O}_{3}$ catalysts used both for $\mathrm{H}_{2} \mathrm{~S}$ decomposition and $\mathrm{SO}_{2}$ reduction have been examined by the XRD technique after reaction [49,51]. Using microwave heating at a measured temperature of $800^{\circ} \mathrm{C}$, an extra crystal structure corresponding to $\alpha-\mathrm{Al}_{2} \mathrm{O}_{3}$ was found in addition to the normal $\gamma$-alumina and $\mathrm{MoS}_{2}$ structures but no $\alpha$-alumina was observed when conventional heating was used. Microwave heating produced significant amounts of $\alpha$-alumina, and 
the XRD peaks were quite sharp, showing that there was a high degree of crystallinity. Since the phase change from $\gamma$ alumina to $\alpha$-alumina is known to occur at temperatures above $1000{ }^{\circ} \mathrm{C}$, and the maximum average temperature recorded in the microwave experiments was $800^{\circ} \mathrm{C}$, it is concluded that microwave heating caused some regions of the catalyst to reach temperatures at least $200{ }^{\circ} \mathrm{C}$ greater than the average temperatures measured by the optical probe.

Scanning electron microscopy examination. Scanning electron micrographs were taken from the catalysts used for the $\mathrm{SO}_{2}$ reduction reaction both before and after reaction. It was found that conventional heating in the furnace during reaction did not cause any significant change in the appearance of the surface or the state of dispersion of the $\mathrm{MoS}_{2}$ particles for both catalysts investigated. However, after microwave heating some of the molybdenum disulfide, which was initially evenly distributed as $152-178 \mu \mathrm{m}$ amorphous particles, formed hexagonal crystals. These are shown for the mechanically mixed catalyst MC-2 in Fig. 12. For the impregnated catalyst the effect of microwave heating was even more marked with extensive formation of hexagonal crystals of $\mathrm{MoS}_{2}$ being observed all over the catalyst.

Compared with the state of dispersion of the $\mathrm{MoS}_{2}$ before reaction it was notable that a considerable migration of $\mathrm{MoS}_{2}$ had occurred. The melting point of $\mathrm{MoS}_{2}$ is $1185^{\circ} \mathrm{C}$, which is some $385^{\circ} \mathrm{C}$ higher than the maximum average temperature recorded in the microwave experiments. This temperature difference is significantly larger than that required to explain the formation of $\alpha$-alumina. However, complete melting may not be necessary to explain the formation of the hexagonal platelets, since this could equally well come about by a rapid rate of migration of $\mathrm{MoS}_{2}$ moieties across the surface.

Furthermore, the extent of the migration occurring during microwave heating was also demonstrated by the for-

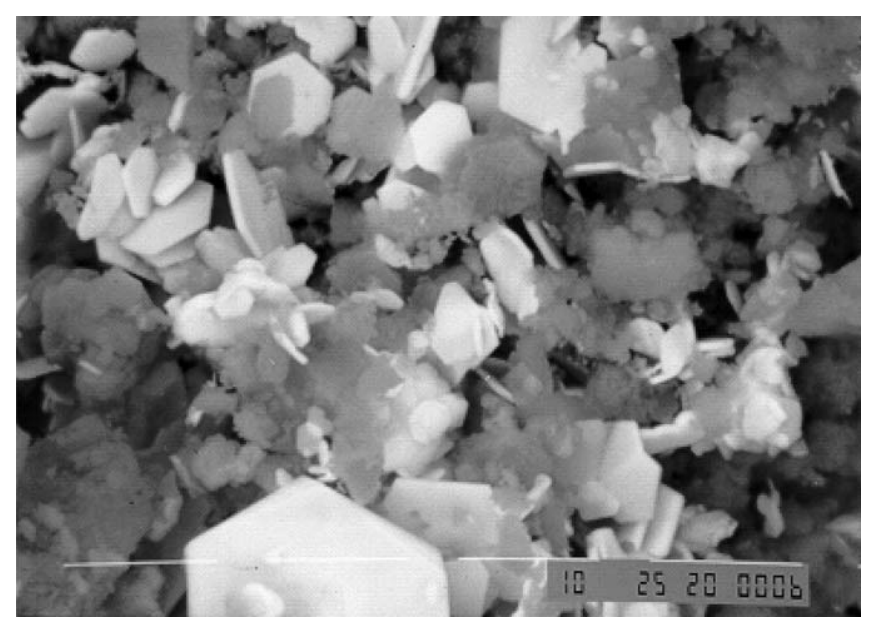

Fig. 12. Scanning electron micrographs of the mechanically mixed catalyst $\left(30 \mathrm{wt} \% \mathrm{MoS}_{2}+\gamma-\mathrm{Al}_{2} \mathrm{O}_{3}\right)$ after reaction under microwave conditions up to $800^{\circ} \mathrm{C}$. mation of spheres of loosely coagulated material with diameters as large as $2 \mathrm{~mm}$. These spheres were found to contain both $\mathrm{Al}_{2} \mathrm{O}_{3}$ and $\mathrm{MoS}_{2}$.

\subsection{Summary}

In summary, a range of evidence has been collected to give an increasingly clear picture of the impact of microwave dielectric heating on chemical processes.

(i) Both theoretical analysis and experimental investigations have shown that there is no such thing as the so called "microwave specific effect", or "non-thermal/ athermal microwave effect" since all results obtained in heterogeneous catalytic systems under microwave conditions can be explained by purely thermal effects.

(ii) The study of endothermic and exothermic reactions using microwave heating have confirmed that thermal effects can be attributed to differences between the reaction temperature and the apparent temperature measured.

(iii) Both theoretical analysis and experimental measurements have shown that it is impossible to maintain a significant temperature gradient at either solid/gas or catalyst/support interfaces under microwave heating. Thus, any hot-spots formed must extend over distances that are much greater than the size of a normal crystallite.

(iv) Examinations of catalysts heated by microwaves have provided methods for estimating the difference between the hot-spot temperature and the average temperature, and for locating the hot-spot within catalyst beds.

Thus, it becomes likely that the spatial-hot spot is the source which caused most of the microwave influence on chemical processes. However, to delineate the question of thermal or non-thermal effects in a satisfactory scientific manner, the importance of temperature monitoring and control cannot be emphasized too strongly [103], although such technique is still under development.

\section{Conclusions}

The applications of microwave dielectric heating in a range of environment-related heterogeneous catalytic reaction systems have been investigated. The results showed significant increases in reaction rates when using microwave heating, as compared to conventional heating at the same nominal temperature. Apparent shifts in the position of equilibrium have also been obtained under microwave heating for three reactions, namely, the decomposition of hydrogen sulfide, the carbon dioxide reforming of methane, and the hydrodesulfurization of thiophene. However, the apparent equilibrium shifts were found to be in opposite directions for endothermic and exothermic reactions. Microwave dielectric heating also resulted in significant 
changes of product selectivities for both the carbon dioxide reforming of methane and the oxidative coupling of methane.

By investigating the interaction of microwave irradiation with heterogeneous catalytic systems and, particularly, the way in which the temperature of the catalyst changes with time it has been possible to deduce that remarkable temperature gradients or hot-spots exist within the catalyst beds. It is the large difference between the hot-spot temperature and the average temperature measured that is thought to be responsible for the acceleration of reaction rates, changes in product selectivities, and the apparent equilibrium shifts. These spatial hot-spots have been confirmed by the examination of catalysts before and after reactions under microwave dielectric heating conditions.

However, to delineate the question of thermal or nonthermal effects in a satisfactory scientific manner, the importance of temperature monitoring and control cannot be emphasized too strongly, but such technique is still under development at present.

\section{References}

[1] A.F. Harver, Microwave Engineering, Academic Press, New York, 1963.

[2] R. Gedye, F. Smith, K. Westaway, H. Ali, L. Baldisera, L. laberge, J. Roussell, Tetrahedron Lett. 27 (1986) 279.

[3] R.J. Giguere, T.L. Bray, S.M. Duncan, G. Majetich, Tetrahedron Lett. 27 (1986) 4945.

[4] M. Bacci, M. Bini, A. Checcucci, A. Ignesti, L. Millanya, N. Rubino, R. Vanni, J. Chem. Soc., Faraday. Trans. 77 (1981) 1503.

[5] N.H. Williams, J. Microwave Power 2 (1967) 123.

[6] ISI Web of Science. http://wok.mimas.ac.uk (accessed 22.08.05).

[7] Evalueserve's Special Reports on Developments in Microwave Chemistry, Chemistry World. http://www.rsc.org/chemistryworld/ Issues/2005/April/MicrowaveChemistry.asp (accessed 22.08.05).

[8] B. Toukoniitty, J.P. Mikkola, D.Y. Murzin, T. Salmi, Appl. Catal. A 279 (2005) 1.

[9] H. Tokuyama, M. Nakamura, J. Syn. Org. Chem. Jpn. 63 (2005) 523.

[10] C.O. Kappe, Angew. Chem. Int. Ed. 43 (2004) 6250.

[11] B. Desai, C.O. Kappe, Top. Curr. Chem. 242 (2004) 177.

[12] V. Santagada, F. Frecentese, E. Perissutti, L. Favretto, G. Caliendo, QSAR Comb. Sci. 23 (2004) 919.

[13] F.D. Wiesbrock, R. Hoogenboom, C.H. Abeln, U.S. Schubert, Macromol. Rapid Commun. 25 (2004) 1739.

[14] K.M.K. Swamy, W.B. Yeh, M.J. Lin, C.-M. Sun, Curr. Med. Chem. 10 (2003) 2403.

[15] I. Roy, M.N. Gupta, Curr. Sci. 85 (2003) 1685.

[16] N.S. Wilson, G.P. Roth, Curr. Opin. Drug Dis. Dev. 5 (2002) 620.

[17] Yu V. Bykov, K.I. Rybakov, V.E. Semenow, J. Phys. D 34 (2001) R55.

[18] A. de la Hoz, A. Diaz-Ortis, A. Moreno, F. Langa, Eur. J. Org. Chem. (2000) 3659.

[19] C.S. Eskilsson, E. Bjorklund, J. Chromatogr. A 902 (2000) 227.

[20] K.J. Rao, B. Vaidhyanathan, M. Ganguli, P.A. Ramakrishnan, Chem. Mater. 11 (1999) 882.

[21] C.R. Strauss, Aust. J. Chem. 52 (1999) 83.

[22] C.S. Cundy, Collect. Czech Chem. Commun. 63 (1998) 1699.

[23] C. Gabriel, S. Gabriel, E.H. Grant, B.S.J. Halstead, D.M.P. Mingos, Chem. Soc. Rev. 27 (1998) 213.

[24] F.E. Smith, E.A. Arsenault, Talanta 43 (1996) 1207.

[25] C.R. Strauss, R.W. Trainor, Aust. J. Chem. 48 (1995) 1665.
[26] A.G. Whittaker, D.M.P. Mingos, J. Microwave Power Electromagn. Energy 29 (1994) 195.

[27] S. Thoma, Chem. Listy 87 (1993) 627.

[28] R.A. Abramovitch, Org. Prep. Proc. Int. 23 (1991) 685.

[29] D.M.P. Mingos, D.R. Baghurst, Chem. Soc. Rev. 20 (1991) 1.

[30] A.K. Bose, B.K. Banik, N. Lavlinskaia, M. Jayaraman, M.S. Manhas, Chemtech 27 (1997) 18.

[31] D.R. Baghurst, A.M. Chippindale, D.M.P. Mingos, Nature 332 (1988) 311

[32] D.R. Baghurst, D.M.P. Mingos, Chem. Commun. (1988) 829.

[33] D.R. Baghurst, S.R. Cooper, D.L. Greene, D.M.P. Mingos, S.M. Reynolds, Polyhedron 9 (1990) 893.

[34] D.L. Greene, D.M.P. Mingos, Trans. Met. Chem. 16 (1991) 71.

[35] D.R. Baghurst, D.M.P. Mingos, J. Chem. Soc. Dalton (1992) 1151.

[36] D.M.P. Mingos, D.R. Baghurst, Brit. Ceram. Trans. J. 91 (1992) 124.

[37] D.M.P. Mingos, Adv. Mater. 5 (1993) 857.

[38] D.M.P. Mingos, Res. Chem. Intermediat. 20 (1994) 85.

[39] A.G. Whittaker, D.M.P. Mingos, Chem. Commun. (1995) 323.

[40] M.M. Chowdhry, D.M.P. Mingos, A.J.P. White, D.J. Williams, Chem. Commun. (1996) 899.

[41] D.R. Baghurst, J. Barrett, E.E. Coleyshaw, W.P. Griffith, D.M.P. Mingos, Mineralog. Mag. 60 (1996) 821.

[42] D.R. Baghurst, D.M.P. Mingos, M.J. Watson, J. Organomet. Chem. 368 (1989) C43.

[43] D.R. Baghurst, D.M.P. Mingos, J. Organomet. Chem. 384 (1990) C57.

[44] A.G. Whittaker, D.M.P. Mingos, J. Chem. Soc. Dalton (1992) 2751.

[45] A.G. Whittaker, D.M.P. Mingos, J. Chem. Soc. Dalton (1993) 2541.

[46] A.G. Whittaker, D.M.P. Mingos, J. Chem. Soc. Dalton (1995) 2073.

[47] A.G. Whittaker, D.M.P. Mingos, J. Chem. Soc. Dalton (2000) 1521.

[48] A.G. Whittaker, D.M.P. Mingos, J. Chem. Soc. Dalton (2000) 3967.

[49] X.L. Zhang, D.O. Hayward, D.M.P. Mingos, Chem. Commun. (1999) 975.

[50] X.L. Zhang, D.O. Hayward, D.M.P. Mingos, Ind. Eng. Chem. Res. 40 (2001) 2810.

[51] X.L. Zhang, D.O. Hayward, C. Lee, D.M.P. Mingos, Appl. Catal. B 33 (2001) 137.

[52] X.L. Zhang, D.O. Hayward, D.M.P. Mingos, Catal. Lett. 84 (2002) 225.

[53] X.L. Zhang, D.O. Hayward, D.M.P. Mingos, Catal. Lett. 88 (2003) 33.

[54] X.L. Zhang, C. Lee, D.M.P. Mingos, D.O. Hayward, Catal. Lett. $88(2003) 129$.

[55] X.L. Zhang, C. Lee, D.M.P. Mingos, D.O. Hayward, Appl. Catal. A 249 (2003) 151.

[56] D.R. Baghurst, D.M.P. Mingos, Chem. Commun. (1992) 674.

[57] A.C. Metaxas, R.J. Meredith, Industrial Microwave Heating, Peter Peregrinus Ltd., London, 1983.

[58] W.R. Tinga, Electromag. Energy Rev. 1 (1988) 1.

[59] E.A. Fletcher, J. Noring, J. Murray, Int. J. Hydr. Energy 9 (1984) 587.

[60] J. Fan, H. Ohashi, H. Ohya, M. Aihara, T. Takeuchi, Y. Negishi, S.I. Semenova, J. Membrane Sci. 166 (2000) 239.

[61] K. Karan, A.K. Mehrotra, L.A. Behie, AICHE J. 45 (1999) 383.

[62] J. Zaman, Fuel Proc. Tech. 41 (1995) 159.

[63] A.Z. Bagautdinov, V.K. Zhivotov, I.A. Kalachev, Sov. Phys. Tech. Phys. 36 (1991) 488.

[64] N. Getoff, Int. J. Hydrogen Energy 15 (1990) 407.

[65] G. Bond, R.B. Moyes, D.A. Whan, Catal. Today 17 (1993) 427.

[66] C. Chen, P. Hong, S. Dai, J. Kan, J. Chem. Soc., Faraday Trans. 91 (1995) 1179.

[67] K.T. Lee, S. Bhatia, A.R. Mohamed, Chem. Eng. Sci. 60 (2005) 3419.

[68] R. Pisani, D.K. de Moraes, J. Hazard Mater. 109 (2004) 183.

[69] S.J. Wu, N. Sumie, C.L. Su, E. Sasaoka, Ind. Eng. Chem. Res. 41 (2002) 1352. 
[70] C.H. Tseng, T.C. Keener, S.J. Khang, J.Y. Lee, Adv. Environ. Res. 3 (1999) 309.

[71] W.Z. Khan, B.M. Gibbs, Environ. Int. 23 (1997) 227.

[72] M.J. Munoz-Guillena, A. Linares-Solano, C. Salinas-Martinez de Lecea, Appl. Surf. Sci. 81 (1994) 409.

[73] K. Kuuspalo, T. Alander, T. Raunemaa, M. Noponen, J. Aerosol Sci. 22 (1991) S471.

[74] V.F. Fischer, H. Tropsch, Brennst. Chem. 3 (1928) 39.

[75] K. Takanabe, K. Nagaoka, K. Nariai, K. Aika, J. Catal. 232 (2005) 268.

[76] W.K. Jozwiak, M. Nowosielska, J. Rynkowski, Appl. Catal. A 280 (2005) 233

[77] D. Treacy, J.R.H. Ross, Stud. Surf. Sci. Catal. 147 (2004) 193.

[78] H.W. Chen, C.Y. Wang, C.H. Yu, L.T. Tseng, P.H. Liao, Catal. Today 97 (2004) 173.

[79] T.C. Xiao, T. Suhartanto, A.P.E. York, M.L.H. Green, Chem. Res. Chin. Univ. 20 (2004) 470.

[80] Z.W. Liu, H.S. Roh, K.W. Jun, J. Ind. Eng. Chem. 9 (2003) 267.

[81] K. Nagaoka, K. Aika, Bull. Chem. Soc. Jpn. 74 (2001) 1841.

[82] V.J. Wargadalam, N.R. Hunter, H.D. Gesser, Fuel Process. Technol. 59 (1999) 201.

[83] R. Bouarab, S. Menad, D. Halliche, O. Cherifi, M.M. Bettahar, Stud. Surf. Sci. Catal. 119 (1998) 717.

[84] O. Weisser, S. Landa, Sulfide Catalysts: Their Properties and Applications, Pergamon Press, Oxford, 1973.

[85] T. Ohtsuka, Catal. Rev. - Sci. Eng. 16 (1977) 291.

[86] R.R. Chianelli, Catal. Rev. - Sci. Eng. 26 (1984) 361.

[87] L. Portela, P. Grange, B. Delmon, Catal. Rev. - Sci. Eng. 37 (1995) 699.

[88] D.R. Stull, E.F. Westrum, G.C. Sinke, The Chemical Thermodynamics of Organic Compounds, Wiley, New York, 1969.

[89] J.K.S. Wan, M.Y. Tse, H. Husby, M.C. Depew, J. Microwave Power Electromagn. Energy 25 (1990) 32.

[90] G. Roussy, E. Marchal, J.M. Thiebaut, A. Kiennemann, G. Maire, Fuel Process. Technol. 50 (1997) 261.

[91] C. Marun, S.L. Suib, M. Dery, J.B. Harrison, M.J. Kablaoui, J. Phys. Chem. 100 (1996) 17866.

[92] Y.I. Pyatnitsky, N.I. Ilchenko, M.V. Pavlenko, Catal. Today 188 (1998) 132.

[93] G.S. Lane, E.E. Wolf, J. Catal. 113 (1988) 144.
[94] C. Gueret, M. Daroux, F. Billaud, Chem. Eng. Sci. 52 (1997) 815.

[95] P. Scholz, B. Ondruschka, Top. Catal. 29 (2004) 175.

[96] W.L. Perry, A.K. Datye, A.K. Prinja, L.F. Brown, J.D. Katz, AICHE J. 48 (2002) 820.

[97] L.D. Conde, C. Marun, S.L. Suib, Z. Fathi, J. Catal. 204 (2001) 324.

[98] C.Y. Cha, C.T. Carlisle, J. Air Waste Manage. 51 (2001) 1628.

[99] J.K.S. Wan, Y.G. Chen, Y.J. Lee, M.C. Depew, Res. Chem. Intermediat. 26 (2000) 599.

[100] G. Roussy, S. Hilaire, J.M. Thiebaut, G. Maire, F. Garin, S. Ringler, Appl. Catal. A 156 (1997) 167.

[101] A. de la Hoz, A. Diaz-Ortis, A. Moreno, Chem. Soc. Rev. 34 (2005) 164.

[102] J. Beckers, G. Rothenberg, ChemPhysChem 6 (2005) 223.

[103] C.O. Kappe (Conv.) Scientific Report, European Science Foundation Exploratory Workshop on Microwave Chemistry and Specific Microwave Effects, Graz, Austria, September 17-20, 2004.

[104] H. Will, P. Scholz, B. Ondruschka, Chem. Eng. Technol. 27 (2004) 113.

[105] C. Shibata, T. Kashima, K. Ohuchi, Jpn. J. Appl. Phys. 35 (1996) 316.

[106] J. Berlan, P. Giboreau, S. Lefeuvre, C. Marchand, Tetrahedron Lett. 32 (1991) 2363.

[107] R. Laurent, A. Laporterie, J. Dubac, J. Berlan, S. Lefeuvre, M. Audhuy, J. Org. Chem. 57 (1992) 7099.

[108] D.A.C. Stuerga, P.J. Gaillard, J. Microwave Power Electromagn. Energy 31 (1996) 87.

[109] D.A.C. Stuerga, P.J. Gaillard, J. Microwave Power Electromagn. Energy 31 (1996) 101.

[110] M. Hajek, Collect. Czech. Chem. Commun. 62 (1997) 347.

[111] G. Roussy, J.M. Thiebaut, M. Souiri, E. Marchal, A. Kiennemann, G. Maire, Catal. Today 21 (1994) 349.

[112] F. Chemat, D.C. Esveld, M. Poux, J.L. Di-Martino, J. Microwave Power Electromagn. Energy 33 (1998) 88.

[113] J.R. Thomas, Catal. Lett. 49 (1997) 137.

[114] G.F. Springer, Advances in Heat Transfer, vol. 7, Academic Press, New York, 1971.

[115] W.L. Perry, D.W. Cooke, J.D. Katz, A.K. Datye, Catal. Lett. 47 (1997) 1. 